\title{
PERAN BUDAYA BOBATU DALAM PENGELOLAAN SUMBERDAYA KELAUTAN DI DISTRIK DEMTA, JAYAPURA, PAPUA
}

\author{
Yusuf Wally \\ Program Magister Sumberdaya Pantai Universitas Diponegoro
}

\begin{abstract}
This paper discusses the values of local wisdom Bobatu and its role in adaptive management of marine resources in the District of Demta. A problem in this connection includes the management of marine resources applied in Indonesia and the centralized nature of the alleged to be one factor affecting the depletion of coastal resources. Supervision and enforcement seem to be weak because of the vast territory, therefore we need an approach to effective management and efficient as well as small scale fisheries management by using the values of local wisdom in the District of Demta in Jayapura in Papua province.
\end{abstract}

Key words: local wisdom, Bobatu, fisheries management, Demta district, Papua.

\section{Pendahuluan}

Isu dan permasalahan pesisir yang umumnya dijumpai di Indonesia termasuk di Kabupaten Jayapura, Papua, antara lain degradasi kualitas ekosistem pesisir akibat destructive fishing dan illegal fishing, terbatasnya infrastruktur dan kapasistas masyarakat (SDM) yang berakibat kemiskinan serta lemahnya aspek kelembagaan akibat sinergitas dan konsistensi kebijakan (Direktorat Jenderal Kelautan dan Perikanan - KKP RI, 2008). Dampak negatif eksploitasi sumberdaya perikanan yang tidak ramah lingkungan berpengaruh pada kegiatan ekonomi perikanan baik pada skala rumah tangga, industri maupun regional. Menurunnya tingkat produktifitas perikanan, tingkat pendapatan nelayan dan kerusakan lingkungan pesisir merupakan indikasi ketidak-seimbagan aspek sumber daya kelautan yang berkorelasi terhadap penurunan kualitas ekonomi masyarakat pesisir dan lingkungan ekologisnya.

Pengelolaan sumberdaya kelautan dan perikanan yang diperlukan meliputi pendekatan pengelolaan sumber daya kelautan dalam skala kecil di pulau-pulau kecil (small island resources management) atau pada komunitas-komunitas masyarakat di pesisir. Pendekatan pengelolaan dilakukan dengan memberdayakan potensi masyarakat lokal untuk dioptimalkan dan diadaptasikan dalam manajement pengelolaan sumber daya kelautan seperti pemanfaatan kearifan budaya lokal untuk keberlanjutan (Andrew, 2007; FAO, 1997).

Tulisan ini membahas bagaimanakah nilai-nilai kearifan lokal Bobatu dan perannya dalam manajemen adaptif sumber daya kelautan di Distrik Demta, Kabupaten Jayapura. Menjadi masalah dalam hubungan ini meliputi, selain kemiskinan dan tingkat kesadaran yang rendah, rezim pengelolaan (Open access \& Common Property) yang diterapkan di Indonesia dan sifat sentralistis diduga juga sebagai salah satu faktor yang mempengaruhi deplesiasi sumber daya pesisir. Pengawasan dan penegakan hukum yang lemah karena luasnya wilayah dan keterbatasan aparat pengawas berakibat kerusakan potensi sumber daya ikan yang susah dikendalikan, yang pada gilirannya berdampak pada aspek sosial-budaya dan ekonomis masyarakat pesisir. Oleh karena itu diperlukan suatu pendekatan pengelolaan yang efektif dan efisien dalam skala 
pengelolaan perikanan yang lebih kecil (small scale management fisheries). Pemberdayaan dan optimalisasi potensi lokal melalui pendekatan manajement adaptif dengan memanfaatkan nilai-nilai kearifan budaya lokal (local wisdom) diharapkan dapat menjadi suatu solusi nyata. Dilibatkan pula dalam pembahasan masalah yang menyangkut rezim pengelolaan sumberdaya kelautan dan perikanan sebagai acuan pembahasan serta konsep dan filosfi budaya Bobatu masyarakat Demta di Kabupaten Jayapura Provinsi Papua.

\section{Sumberdaya Kelautan dan Fungsinya}

Sumberdaya kelautan merupakan segenap potensi sumber daya yang terdapat di laut. Sumberdaya tersebut terdiri atas sumber daya dapat pulih (renewable resources) seperti ikan dan ekosistem pesisir dan laut, sumberdaya tidak dapat pulih (non-renewable resources) seperti mineral tambang di dasar laut dan jasa-jasa lingkungan kelautan (environment service) yang dapat dimanfaatkan bagi kelangsungan dan kesejahterahan hidup manusia seperti media transportasi, keindahan alam bawah laut dan pantai, energi alternatif dengan memanfaatkan energi kinetik arus dan pasang laut, Ocean Thermal Energy Conversion (OTEC), dan konversi energi dari perbedaan salinitas (Dahuri, 2001).

Sumberdaya laut dan pesisir yang dapat pulih seperti ekosistem bakau (mangrove), lamun dan terumbu karang serta ekosistem laut dalam tidak saja memiliki potensi keanekaragaman hayati tetapi juga memiliki fungsi ekologis, fungsi sosial dan ekonomis, karena dapat menyediakan berbagai kebutuhan berbagai organisme laut dan darat, juga termasuk manusia.

Fungsi ekologis, sosial dan ekonomis tersebut serta jasa lingkungannya menjadikan wilayah laut dan pesisir sebagai sumber penghidupan dan tempat hidup bagi manusia (Dahuri, 1996; Rohmimohtarto, 2007).
Produktivitas sumber daya perikanan sangat bergantung pada keberadaan ekosistem laut dan pesisir. Bila ekosistem pesisir yakni estuaria, hutan bakau, padang lamun, dan terumbu karang rusak maka tidak dapat lagi menunjang produktivitas perikanan. Hal ini sangat beralasan karena produktivitas primer rata-rata perairan pesisir dapat mencapai lebih dari $500 \mathrm{~g}$ C/m2/tahun (Mann, 1982). Nilai produktivitas primer tersebut sangat tinggi dibandingkan dengan produktivitas primer laut dangkal pada umumnya, yaitu sekitar $100 \mathrm{~g} \mathrm{C} / \mathrm{m} 2 /$ thn atau diperairan laut dalam yang hanya sekitar $50 \mathrm{~g} \mathrm{C} / \mathrm{m} 2 /$ tahun (Ryther, 1959). Hal ini memberi arti bahwa potensi kelautan dan perikanan sangat penting artinya bagi kehidupan masyarakat pesisir.

\section{Manajemen Adaptif}

Secara mendasar manajement adaptif sumberdaya kelautan merupakan suatu upaya pendekatan pengelolaan yang memanfaatkan segenap potensi karakteristik biofisik, sosial- budaya dan ekonomi komunitas masyarakat pesisir sebagai suatu adaptasi dalam mengelola dan memafaatkan potensi sumberdaya laut untuk memenuhi kebutuhan hidup secara berkelanjutan.

Sebagaimana didefinisikan oleh Graham dan rekan (2006), management adaptive pengelolaan sumberdaya kelautan dan perikanan memiliki makna:

Fundamentally, community-based fisheries management is a very simple idea, arising out of a key reality: fishermen and coastal communities, being the most dependent on coastal and marine resources, should have a large role in deciding how these resources should be managed. This idea fits within an emerging understanding that management decisions of all sorts are often best made at the most local level possible (Graham et al, 2006).

Oleh karena itu ciri dari manajement adaptif adalah keluasan peran masyarakat pesisir (coastal community) dalam menentukan bentuk pengelolaan yang objektif sesuai kemampuan dan pemahaman mereka secara lokal tentang 
karakteristik biofisik (ekologis), karakteristik sosial, budaya dan ekonomi. Adaptasi pengelolaan menempatkan komunitas masyarakat pesisir sebagai subjek sehingga mereka berperan secara bersama-sama mengidentifikasi, merumuskan, merencanakan dan melaksanakan rencana pengelolaan dan pemanfaatan sumber daya kelautan sesuai karakteristik dan kebutuhan mereka untuk saat sekarang dan masa yang akan datang dengan dukungan pemerintah (local authority) sebagai fasilitator (Wamebu, 2004; Soumanpouw, 2004).

\section{Kearifan Lokal}

\section{United Nations Environment Programme (UNEP) mendefinisikan kearifan lokal secara luas sebagai pengetahuan masyarakat (lokal) adat yang terakumulasi selama beberapa generasi, yang hidup dalam lingkungan tertentu termasuk pengertian semua bentuk pengetahuan, teknologi, keterampilan teknis (know-how skills), praktek dan keyakinan, yang memungkinkan masyarakat untuk mencapai kehidupan yang tetap atau stabil pada lingkungan mereka (http://www.unep.org/ik).}

Dalam pengertian yang sama Prof. Dr. L. Jan Slikkerveer (2011) seorang guru besar Universiteit Leiden mendefiniskan dan menjelaskan indigenious knowledge, sebagai memiliki pengertian yang mencakup kebiasaan, pengetahuan, persepsi, norma, kebudayaan yang dipatuhi bersama suatu masyarakat (lokal) dan hidup turun-temurun. Kearifan Lokal itu bisa meliputi bidang etika, kesehatan, sosialkemasyarakatan, cara-cara bertani, memelihara kelestarian lingkungan, termasuk sumber daya kelautan dan perikanan.

$\begin{array}{ccc}\begin{array}{c}\text { Sistem } \\ \text { kebudayaan }\end{array} & \text { yang menjadi } \\ \text { selanjutnya, } & \text { menurut }\end{array}$ Mansoben (2010), mengandung norma-norma dan aturan-aturan tentang bentuk dan sifat dari relasi-relasi yang dijalin oleh para warga masyarakat dalam suatu kebudayaan tertentu untuk saling berinteraksi dalam rangka mewujudkan kehidupan bersama. Dalam hal ini kebudayaan mengatur hak dan kewajiban para warga masyarakat berdasarkan kedudukan dan peran mereka masing-masing.

Kebiasaan, norma-norma, pengetahuan dan nilai-nilai kearifan lainnya yang hidup, berlaku dan mempengaruhi cara pandangnya kemudian akan menjadi sebuah sistem nilai dan terdiri dari konsepsi-konsepsi yang hidup dalam alam pikiran sebagian besar warga masyarakat, tentang berbagai hal yang dianggap sangat bernilai dalam hidup. Karena itu, suatu sistem nilai budaya biasanya berfungsi sebagai pedoman tertinggi bagi perilaku manusia, sebagai bagian dari adat-istiadat dan wujud ideal dari kebudayaan. Sistem nilai-budaya seolah-olah berada di luar dan di atas dari para individu yang menjadi warga masyarakat yang bersangkutan (Koentjaraningrat, 1981: 25, dalam Apomfires, 2002).

\section{Lokasi: Distrik Demta}

Distrik Demta terletak di sebelah selatan bibir Samudera Pasifik, tepatnya di sebelah utara Kabuapaten Jayapura. Jumlah penduduk Demta 3321 jiwa: 1692 pria dan 1629 wanita yang tersebar di 7 (tujuh) kampung, yakni Kampung Demta, Ambora, Yougapsa, Muris Kecil, Yakore, Kamdera dan Muaif (http://www.jayapurakab.go.id). Masyarakat yang mendiami Demta awalnya adalah suku-suku yang dulunya berasal dari bagian Demta gunung dan bagian kelompok lainnya yakni Demta Pantai. Setelah masuknya gereja dan masa pendudukan kolonial Belanda suku-suku tersebut dikumpulkan menjadi satu di pesisir dan mempunyai hak yang sama atas pemanfaatan laut. Suku-suku yang mendiami wilayah Demta tersebar di 3 (tiga) kampung, yakni 1) Kampung Ambora terdiri dari suku-suku Tunya, Eybe, Karafir, Darinya, Tier, Dodop, Papiri, Ipungkawa, Kowan, Pila, Koasi, Buara, Ipun; 2) Kampung Muris terdiri dari suku-suku Yaukwar, Yakore, Arim, Burame, Kopouw, Mandai, Sobri, Pararem, Murunggu, dan Okobron; dan 3) Kampung Yogapsa dan Tarpia ditempati suku-suku Usupar dan 
Pica, Daisiu, Taudufu, Tauruy, Fetowin, Ondi, dan Bernifu (wawancara Maker, 2011).

Batas-batas wilayah kampung ke arah laut dimulai dari daerah perairan yang dangkal hingga daerah peralihan antara laut dangkal dan laut dalam (biru) yang tidak bisa dilihat dasar perairannya. Batas laut dan kampung ditentukan secara imajiner, ditandai oleh teluk, pulau atau tanjung dan sistem komunal yang dianut mengukuhkan pemimpin suku-suku dengan sebutan Ondoafi sedangkan batas wilayah di darat ditentukan berdasarkan legenda atau cerita orang-orang tua dan bekas hasil karyanya. Saat ini sesuai perkembangan dan dinamika sosial dan politik suku-suku telah diakomodir dalam wadah atau lembaga Masyarakat Adat, di kawasan Demta disebut Dewan Adat Suku (DAS) Demta (Anonym, 17 Juni 2011).

\section{Bobatu}

\subsection{Budaya Bobatu dan Filosofinya}

Budaya Bobatu merupakan suatu kebiasaan turun-temurun yang diajarkan atau diwariskan oleh orang-orang tua dahulu kepada generasi masyarakat beberapa suku yang mendiami wilayah Distrik Demta Kabupaten Jayapura tentang cara pemanfaatan ikan-ikan batu (ikan karang) secara bersama-sama. Nilai-nilai filosofi budaya Bobatu relatif sederhana namun secara implisit telah mencakupi suatu pemahaman teknologi manajemen perikanan yang maju. Nilai-nilai atau filosofi budaya Bobatu, menurut Maker Anthon (wawancara, 2011) dan Daud Yakwar (wawancara, 2010) sebagai berikut.

1) Sumberdaya ikan dan laut merupakan sumber kekayaan dan kehidupan bersama yang diberikan Tuhan.

2) Ada masa-masa tertentu di mana ikan (ikan karang) akan besar dan bertambah banyak dan hanya boleh diambil atau ditangkap jika ikan dianggap sudah besar.

3) Pengaturan \& pemanfaatan kekayaan laut diatur oleh pemimpin suku yang disebut Ondoafi, dan bagi yang melanggar mendapat hukuman secara adat.
4) Ikan karang dipanen setelah dilakukan penutupan atau pelarangan penangkapan selama 6 bulan hingga 1 tahun. Pemanenan dilakukan secara bersama-sama oleh seluruh anggota kampung dan juga mengundang saudara-saudara atau masyarakat dari kampung-kampung di dekatnya.

5) Manusia dan sumber kekayaan laut (ikan) memiliki ikatan historis (secara antropologis). Terdapat keret-ketet yang dinobatkan sebagai "orang laut" dan memiliki ikatan magis dengan laut dan dapat menjadi pawang untuk memanggil ikan.

6) Upacara atau kebiasaan ini dilakukan juga pada hari-hari besar keagamaan (natal kampung, dan lain-lain), pelantikan Ondoafi dan kunjungan tamu istimewa atau acara-acara kampung yang banyak melibatkan orang.

\subsection{Peran Bobatu dalam Pengelolaan Sumberdaya Berkelanjutan \\ Kelautan}

Untuk melihat sejauh mana peran budaya Bobatu dalam pengelolaan sumberdaya kelautan dan perikanan, akan dibahas masing-masing nilai atau filosofinya dengan manajemen kelautan dan perikanan konvensional.

\subsubsection{Sumberdaya Ikan dan Laut sebagai Kekayaan/Kehidupan Bersama yang Diberikan Tuhan}

Pandangan hidup ini sering terlihat dari keikhlasan hati masyarakat nelayan lokal dan tokoh-tokoh adat dan masyarakat ketika mengijinkan nelayan luar dari wilayah perairan kampungnya untuk menangkap ikan. Pandangan ini didasari oleh pemahaman bahwa laut merupakan "milik kita bersama." Dalam pandangan "milik kita bersama" tidak berarti laut dapat dieksploitasi semaunya, tetapi telah diatur sesuai kesepakatan mereka, termasuk jumlah dan ukuran ikan yang boleh ditangkap; penangkapan ikan tidak boleh dengan cara merusak karang dan 
lingkungan. Bagi orang luar Demta jumlah ikan yang diambil tidak boleh melebihi batas konsumsi dan kebutuhan untuk dijual. Setiap orang luar yang hendak menangkap ikan harus meminta ijin (kasih suara) kepada tokoh masyarakat/adat setempat. Setiap pelanggaran oleh masyarakat Demta dan orang dari luar Demta ada hukumannya secara adat dengan bayar denda berupa uang atau hasil kebun dan/atau menangkap babi.

\subsubsection{Pengaturan \& Pemanfaatan Kekayaan Laut Diatur oleh Pemimpin Suku atau Ondoafi}

Pengaturan dan pemanfaatan sumber daya laut (ikan karang) disepakati bersama di bawah arahan dan pimpinan seorang kepala suku, Ondoafi, tokoh adat. Dalam kesepakatan ini nilai kebersamaan selalu dijunjung, setiap keputusan untuk mengakomodir semua kepentingan.

\subsubsection{Ikan Karang Dipanen Setelah Dilakukan Penutupan atau Pelarangan Penangkapan Selama Beberapa Saat Lamanya (6 Bulan hingga 1 Tahun)}

Hal ini jelas menunjukkan betapa kearifan lokal telah juga menjustifikasi dengan baik sebuah siklus secara biologi perikanan bahwa fase hidup ikan diberi ruang dan waktu tanpa ada tekanan dari luar bagi pertumbuhan dan perkembangbiakan ikan-ikan karang. Dalam manajement perikanan, penangkapan ikan ukuran dewasa atau dengan ukuran tertentu merupakan upaya untuk melestarikan sumberdaya ikan; kesempatan rekruitmen ikan-ikan yang masih mengalami masa pertumbuhan tetap tejaga sedangkan ikan yang ditangkap adalah populasi ikan ukuran dewasa (virtual population).

\subsubsection{Manusia dan Sumber Kekayaan Laut (Ikan) Memiliki Ikatan Historis (secara antropologis).}

Terdapat keret-ketet yang dinobatkan sebagai "orang laut" dan memiliki ikatan magis dengan laut sehingga dapat menjadi pawang untuk memanggil ikan. Dalam tahapan upacara budaya Bobatu terdapat beberapa suku yang paling bertanggung jawab, misalnya suku Eybe: suku ini memiliki kemampuan untuk melaksanakan prosesi pemanggilan ikan gaji (Julung/Dermogenys pusilla), setelah prosesi pengumpulan ikan dari celah batubatu karang selesai dengan menggunakan akar tanaman bobato (omar, bahasa ambora yakni sejenis akar tuba) dan ditangkap menggunakan jaring. Ikan julung (Dermogenys pusilla) bagi masyarakat Demta secara turun temurun dianggap sebagai ikan penting karena ikan tersebut dianggap dapat memanggil jenis ikan-ikan lain datang ke wialyah penangkapan ikan di perairan kampung sehingga ikan ini dianggap sebagai indikator biologi dalam menilai kondisi perairan. Ikan julung yang boleh ditangkap adalah ikan yang berukuran besar (dewasa). Suku Eybe berperan sebagai pawang yang mampu memanggil ikan julung.

Kearifan budaya Bobatu dalam menilai kondisi perairan dengan menggunakan indikator biologi merupakan suatu pengetahuan lokal ekologis (local ecologic knowledge) yang sangat bernilai, hal ini dapat dikembangkan melalui pengelolaan perikanan secara adaptif dalam upaya pengelolaan sumberdaya perikanan di Kabupaten Jayapura.

ikan jubungan sifat biologis dan ekologis memberikan justifikasi atau penjelasan terhadap panangan (local ecologic knowledge) tersebut. Secara bio-ekologis ikan julung merupakan pemakan rumput laut, ganggang hijau dan berkembang biak di estuarin, banyak ditemukan di perairan pesisir pulau yang tinggi dan garis pantai benua, umumnya di daerah yang banyak terdapat vegetasi air seperti rumput laut, alga hijau, dan lain-lain dan dasar berpasir dan dapat hidup pada habitat dengan kisaran $\mathrm{pH} 7.0-8.0$ dan suhu $24-28^{\circ} \mathrm{C}$ atau dengan kata lain terdapat pada daerah beriklim tropis. Tergolong ikan pelagis besar, biasa hidup bergerombol, ikan ini termasuk ikan herbivore yang berkembang biak di lingkungan estuarin atau muara. Wilayah penyebarannya terdapat di permukaan pantai, lepas pantai terutama Indonesia Timur (Laut Flores, Selat 
Makassar, Laut Sulawesi, Laut Maluku, Laut Banda) dan perairan yang berbatasan dengan Samudera. Sifatnya sebagai ovovivipar, telur yang dibuahi di dalam tubuh ikan betina. Pada jenis ikan lain pembuahan terjadi di luar tubuh betina. Di dalam kandungan betina, telur akan mengalami perkembangan janin, sampai tahap siap dilahirkan dan hidup di air (http://www.fpik.undip.ac.id/perikanan/biodiv ersity/).

Dari fakta bio-ekologis di atas dapat diduga dan disimpulkan bahwa hubugan rantai makanan dan status keberadaannya dalam struktur trofik sebagai konsumer tingkat II (ikan pelagis) sangat berperan penting dalam eksosistem laut dan ekosistem perairan pesisir (off shore).

\section{Simpulan dan Saran}

Sebagai kearifan budaya lokal, budaya Bobatu memiliki beberapa nilai positif maupun nilai negatif. Nilai-nilai positif yang dapat dikembangan dalam upaya pengelolaan sumberdaya kelautan dan perikanan yang adaptif di skala komunitas lokal (small island management approach ) adalah sebagai berikut.

1) Sumber daya ikan (kekayaan laut) merupakan milik bersama namun tidak berarti dapat dieksploitasi semaunya sehingga mesti diatur (jumlah dan ukuran ikan, dan orang di luar suku-suku di Demta) mulai pada tingkat lokal (kampung) dengan dukungan pemerintah (local autority), dimana nilai-nilai kearifan lokal lebih dikedepankan.

2) Penangkapan ikan tidak boleh dilakukan dengan cara merusak karang/lingkungan sumber daya ikan.

3) Penangkapan ukuran ikan dewasa dengan ukuran tertentu merupakan upaya untuk melestarikan sumber daya ikan, kesempatan rekruitment ikan-ikan yang masih mengalami masa pertumbuhan tetap tejaga sedangkan ikan yang ditangkap adalah ukuran populasi dewasa (virtual population).

4) Kearifan budaya Bobatu dalam menilai kondisi perairan dengan menggunakan indikator biologi merupakan suatu pengetahuan lokal ecologis (local ecologic knowledge) yang sanagat bernilai, hal ini dapat dikembangkan melalui pengelolaan perikanan secara adaptif dalam upaya pengelolaan sumberdaya perikanan di Kabupaten Jayapura.

Sedangkan hal lainnya yang dipandang negatif dalam budaya Bobatu adalah menyangkut prosesi pelaksanaan tumbuk batu atau tangkap ikan dan bahan akar bobati (= omar, bahasa Ambora). Prosesi penangkapan ikan batu berpotensi merusak terumbu karang hidup (diinjak/ditusuk-tusuk saat mengusir ikan). Hal berikutnya adalah penggunaan bahan akar bobato (sejenis tumbuhan akar tuba) yang berdampak buruk bagi jenis dan bibitbibit ikan kecil. Oleh karena itu diharapkan agar dalam perlaksanaan budaya Bobatu, bahan akar bobato dapat digantikan dengan bahan yang tidak bersifat racun, saat pelaksanaan penangkapan ikan keberadaan terumbu karang jangan dirusak dengan cara diinjak-injak atau ditusuk atapun batunya dibalik-balik. Hal ini dimaksudkan agar karang sebagai rumah ikan tersebut tidak rusak atau mati.

\section{Daftar Pustaka}

Andrew, N., Béné C., Hall S. J., Allison E. H., Heck S. and Ratner B.D. 2007. "Diagnosis and management of small-scale fisheries in developing countries." Fish and Fisheries 8.

Anonym, 2011. Berita: "32 Tahun Jalan ke Demta Rusak Berat." Tabloid Jujur Bicara (JUBI), edisi 17 Juni, Jayapura.

Apomfires, Frans. 2002. "Makanan pada Komuniti Adat Jae: Catatan SepintasLalu dalam Penelitian Gizi." Jurnal Antropologi Papua. Jayapura: Universitas Cenderawasih. Volume 1, No. 2. Edisi 2 Desember. 
Charles, A. T. 1993. "Towards Sustainability: The Fishery Experiences." Ecological Economics Vol 11 pp. 201-211.

Dahuri, R. 2003. "Paradigma Baru Pembangunan Indonesia Berbasis Kelautan." Orasi IImiah Guru Besar Tetap Bidang Pengelolaan Sumberdaya Pesisir dan Lautan, Fakultas Perikanan dan IImu Kelautan, IPB.

Dahuri, R., J. Rais, S.P. Ginting dan M. J. Sitepu. 1996. Pengelolaan Sumberdaya Pesisir dan Lautan Secara Terpadu. Jakarta: PT Pramadya Paramita, Jakarta.

FAO Fisheries Department. 1997. Review of the State of World Fishery Resources: Marine Fisheries South Pacific Island (FAO FAO Statistical Areas 71 and 7) Rome: FAO Fisheries Circular No. 920 FIRM/C920, ISSN 0429-9329.

Fauzi, Akhmad. 2010. Ekonomi Perikanan - Teori, Kebijakan dan Pengelolaan. Jakarta: Gramedia Pustaka Utama.

Kiara, 2010. Artikel News diunduh dari web: www.kiara.or.id/content/vieuw/1111574/ (Jakarta, 2 Undang-undang RI Nomor 31 Tahun 2004 tentang Perikanan (kemudian direvisi dengan Undang-undang Nomor 45/2009).

Mann, K.H. 1982. "Ecology of Coastal Waters: a System Approach," in Anderson, D.J., P. Greic-Smith, and F.A. Pitelka (eds.) Studies in Ecology, vol.8. University of California Press, California.

Mansoben, J. R. 2010. "Kebudayaan dan Pembangunan dalam Kerangka Otonomi Khusus," Simposium Nasional Papua: Menuju Pembangunan Berbasis Masyarakat yang Berkelanjutan. Kerjasama FISIP Universitas Indonesia, Jakarta dan FISIP Universitas Cenderawasih. Jakarta, 7-9 April.

Ryther, J. H. 1959. "Potential
Productivity of the Sea," Science 130: 602608.

Slikkerveer, L. Jan. 2011. "Bincang Malam: Kearifan Lokal" (Siaran Televisi Republik Indonesia Edisi 07 Mei 2011). Guru Besar Universiteit Leiden, Belanda.

Soumampaouw, Monique, Jacob Rais, Budi Sulistiyo, Son Diamar, Tiene Gunawan, Tjoek Aziz Suprapto, Idwan Suhardi, Asep Karsidi, M. Sidit Widodo. 2004. Menata Ruang Laut Terpadu. Jakarta: PT Pradnya Paramita.

Wamebu, Zadrak. 2004. Peran Serta Masyarakat dalam Penyusunan Perencanaan Pembangunan Daerah yang Partisipatif. Regional Manager Perform Project PDPP Papua (Aktifis Senior LSM Papua). Artikel, Jujur Bicara (JUBI) No. 6869 Tahun 05, edisi 21 Februari-06 Maret 2004. Jayapura.

\section{Sumber Web Internet}

http://www.fpik.undip.ac.id/perikanan/ biodiversity/shared/biblio view.php?resourc e id=67\&tab=opac.

http://www.jayapurakab.go.id/index.ph p?searchword=keadaan+Distrik+demta

\section{Wawancara}

1). Daud Yakwar, 2010. Ketua Dewan Adat Suku (DAS) Demta, Daud Yakwar, wawancara pribadi tentang "Peran NilaiNilai Budaya Lokal/Adat dalam Kegiatan Sosialisasi Pengawasan Sumber Daya Kelautan di Distrik Demta Kabupaten Jayapura" (16 Mei 2010) Bidang Pengawasan Sumber Daya Kelautan Dinas Kelautan dan Perikanan Provinsi Papua, Jayapura.

2). Maker Anthon, 2011. Kepala Sekolah SMTP Negeri 1 Demta di Ambora, Demta, Kabupaten Jayapura. Wawancara pribadi tentang "Pengalaman dan Pandangan Budaya Bobatu bersama Masyarakat Demta sebagai Guru" (2011). 